\title{
The Effects on Reader Services of Applying Blogs in High School Libraries in Taiwan
}

\author{
Sheng- Shyong Jheng \\ Graduate Student \\ Graduate Institute of Library and Information Studies, \\ National Taiwan Normal University \\ R. O. C. (TAIWAN) \\ Yu-Hsiu Lai \\ Graduate Student \\ Graduate Institute of Library and Information Studies, \\ National Taiwan Normal University
}

R. O. C. (TAIWAN)

\begin{abstract}
The aim of this study is to explore high school library blogs in terms of its construction, purposes, contents and influences to reader services in Taiwan. Ten highly- represented high school library blogs were chosen and compared by using content analysis and interview methods. The findings suggested that the majority of the blog content in high school libraries focus on promoting reading activities. Second, the purposes of constructing library blog are to announce library-related news, provide students a reading environment, and to coordinate with teachers' instructional activities. Third, the most distinctive influence of library blog in terms of reader services is the extension of communication channel and simplification of announcement procedure. Fourth, more than half of the high school library blogs have reached their expected goals on reader services. Finally, most of the high school libraries are intended to continuingly maintain their blogs toward multiple services direction. Based on above findings, the study has reached the conclusion that the construction of blog is indeed helpful to enhance library reader services. However, the support of school authorities is the key factor on whether the application of blog can be successful to high school libraries.
\end{abstract}

\section{Introduction}

Through the common use of Computer and Internet on library services, more and more new information technologies are being employed in the library. Those new technologies have brought a great impact on library services and management; for example, on-line inquiry, document delivery services, and database retrieval. Blog is one of the most significant forms of communication. Blog, developed from the Web, is similar to a personal Web Page. It offers a straightforward annunciation platform, and an on-line live conversation, including Permalink, Comments, and Trackback. The flexibilities, conveniences, and multiplicities of blog have been applied in many areas, such as company's internal discussion, news update, digital learning, advertisement, and RSS network.

Besides the routine jobs, such as providing the services of reading and circulation, the high school librarians, who are responsible for the reader services, need to teach the teachers and the students how to use the school library, and to cooperate with the teaching activities at 
the school. Resources and times offered by the school are limited, so it is logical for the high school libraries to manage their work with blogs.

The use of blog in libraries, on one hand, can reduce the librarians' burden of serving the readers; on the other hand, the readers can post and share their interesting articles and ideas. But, what kind of contents should be posted on blogs? What are the advantages and disadvantages of blogs? Or blogs may even face few or no users due to mismanagement. All the above issues need to be considered prior to the development of the blogs. Therefore, this study focuses on the existing blogs in high school libraries in Taiwan for our study. After getting familiar with the contents of the library blogs, librarians will be interviewed in terms of the purpose of setting up blogs and their influences on reader services in order to understand blog usage in high school libraries.

\section{Literature Review}

To explore the development and the usage of the blog in high school libraries, and to probe the problems associated while using the blog, the existing literature on this topic has been collected.

Blog is a new digitized communication channel. Users can express their personal thoughts through the blog on internet. The contents of the blog can be posted accordingly and can be updated continuously. According to Harder \& Reichardt (2003), "Blogs may be generalized to mean regularly updated web pages."

Fichter (2001) mentioned, "By producing a Weblog, a library can showcase expertise on a particular topic to enhance the library's reputation as a source of authoritative information." While Harder \& Reichardt (2003) suggested that libraries should pay much attention to the trend of blog's development and propose the feasible approach to apply blog in libraries. For example, the public libraries can set up specific blogs, like Parents' advisory weblog, Children's book review weblog, and Virtual book club / readers' advisory weblog. The academic libraries, on the other hand, can set up Faculty / departmental advisory, and Suggestion box weblog. "A blog can constantly underscore the importance of freely available information and the people who acquire, disseminate, classify, organize, and retrieve information. Blogging software is easy to use and very flexible." (LaMee, 2005). Blog not only provides a channel for readers to comment, disseminate, and reprint information (use the Permalink function), but also helps the students to enhance their online critical-thinking skills and information literacy skills (McPherson, 2006). In addition, the libraries can convert the disposable message into extended information by using blog (e.g. for the reference to edit the history of the library).

Correlations between the blog content and the readers in libraries have also been found. For example, the public libraries usually provide diverse services according to different ages or different groups of readers. The Community Information of Johnson county library provides the local readers with the news about the council and the local information like recycling of Christmas trees (Tu\& Ke, 2006). "The 2003 survey revealed that the most common use of the library weblogs was for providing news and updates for library users, particularly about print and Internet resources; 44 percent provided information about functions, activities and events in the library." (Clyde, 2004). While in the 2004 survey, Clyde found that, "As was the case with library weblogs in general, these school library weblogs were being used to provide information about library activities and resources, to 
highlight useful resources on the Internet, and, in some cases to make book reviews available online." They tended to be a one-way medium of communication from the library to its users. Michael Stephens (2006) classified the services of library blog into three categories: 1. Library News Blogs, 2. Marketing and Promotion Blogs, and 3. Materials / Resources Blogs. However, to satisfy the readers is the objective of the library, what all the librarians do for the readers is to help them get the information they require (Seng, 1992). No matter what the type of library blog is, the primary consideration has to be what the readers need and accept, and the next step is how to develop the library blog to attain the aim of serving readers.

Referring to the articles of "The development and application of Library Blog" (Wang \& Yang, 2006) and "Blogs for Public libraries" (Tu and Ke, 2006) and other related articles, most blogs are managed by individuals, but more and more libraries have used blogs to promote several kinds of services. To sum up, the major contents of library blogs are: (1) to provide information about news and messages (bulletin board), (2) to provide information about book recommendation and review, (3) to provide information about reference resources, (4) to recommend Internet resources, (5) to establish the book club, and (6) to provide a channel for communicating and sharing. The benefits for the libraries include division of business, prompt updating, quality promotion, immediate dissemination, direct communicating, and multiple viewpoints.

Empirical research on applying blogs in Taiwanese libraries is limited (Wang, 2006). To understand the viewpoint of librarians about applying blogs in the libraries, Wang conducted documentary analysis, web questionnaire inquiry, and case study to exploit and analyze the involvement of blogs, how the blogs were used and how the blogs were set up through quantification and qualification. The result showed that the university librarians have had the experience of establishing personal free blogs, the university libraries themselves have set up blogs to extend their services or to diversify the approaches of services, the welldeveloped blogs applied in the university libraries in the USA can be taken for our reference, the libraries should integrate all kinds of functions in the blogs with library services to improve the range of visibility of information services.

Among the related articles, the research about the influence of setting up blogs in high schools is relatively less compared to the blogs in the public libraries and university libraries. Since the high school libraries play essential roles during the basic education phase, this study analyzes the effect on the services to the readers after setting up the blogs in high school libraries.

\section{The Purposes and Research Questions of the study}

This research makes an attempt to answer the following questions:

(1) What are the main contents of the blogs in high school libraries?

(2) What are the purposes of setting up blogs in high school libraries?

(3) What are the effects on the original reader services after setting up the blogs in high school libraries?

(4) Does it reach the anticipant objectives about the reader services after setting up the blogs in high school libraries? 
(5) What are the future directions of management about the blogs in high school libraries?

\section{Methodology}

The author has conducted interviews with the librarians over phone or face to face about their perspectives on the purposes of the setting up the blogs in high school libraries, the effects on the services to the readers, and the future management.

The targets of this study are based on the website of the Ministry of Education listings (Department of statistics, Ministry of Education, R. O. C., 2007). In Taiwan, junior, senior, technical and vocational high schools use the blog in their libraries. The school library websites can be linked to explore the use of blogs in high school libraries; the exploration period was from February 1, 2007 to March 31, 2007. This study has taken ten samples from the high school libraries that have been updating their blogs in six months. They are: Cheng Yuan High School, Ping Jhen High School, Chu Tung Senior High School, Hua Jiang High School, Wen Hua Senior High School, Sha Lu Industrial Vocational Senior High School, Ming Dao High School, Tian Mu Junior High School, Shihkang Junior High School, and Xi Hu Junior High School. The service contents of the blogs in the library provided by the above schools are then analyzed. Next, the person who is in charge of the blogs is interviewed. Because of the time limitation and the willingness of the librarians, we have taken one interviewer from each library. There were ten librarians, and the interview period was from March 26th, 2007 to March 31st, 2007.

\section{Results}

The following results have been obtained:

\section{(1) Main contents of the blogs in high school libraries}

The major contents of the blogs in high school libraries emphasize on the promotion of reading. The following is the observation about the function and the service content of each blog of the school library:

With regard to the function of the blog, all of the 10 blogs provide "posting articles and news", "announcing dates and time" to fulfill the function of the blog at any time and to hold the announcing time. The user can obtain the most recent information, which they are interested in by subscribing RSS, or the user can understand the most recent articles through the function "notice of new articles" (nine of ten). In addition, the user can also use "resources link function" (three of ten) and "blog link function" (four of ten), to expand the opportunity of using information. After the comparison, we can also find that almost all of the blogs of the ten high school libraries possess the following functions: "blog searching function", "Trackback function", "comment interaction function" to issue the news, to retrieve, to trackback, to comment and to interact. As for the software, which is used by the most libraries include Life Type, the next are Movable Type Publishing Platform, PJBlog2, and Tatter Tools. Moreover, the only adopted network service business is Yahoo Blog.

As for the contents of the library services (see table 2 and chart 2), not all the blogs show the names (seven) and information of the library as well as links the library website 
(approximately a half proportion). The major reason the blogs which show the library names is that such blogs have substituted the original library websites, while the blogs don't show library names are intended to make a differentiation between the blogs and the library websites. Approximately half of the blogs can link with the library websites; nevertheless, there are still less than half of the blogs which provide the collection information for the users to acquire. In addition, seven blogs of the libraries provide news about the library activities, and all library blogs (ten) provide information about new books. It is clear that high school libraries attach great importance to reading; hence the libraries provide only introductory information about new books. Besides the introduction of the books, many library blogs also posses the network resources link function and the on-line book club function (eight) for the users to extend their study and learning. Regarding "on-line comment interaction function", it shows the high school libraries still have to reinforce the supply and unimpeded channels of the contact information.

Table 1. Statistics of the blog functions in Taiwanese high school libraries

\begin{tabular}{|c|c|}
\hline Type of functions & Numbers (the ratio of each function item to the amount) \\
\hline Time and date & $10(100 \%)$ \\
\hline Articles or news & $10(100 \%)$ \\
\hline RSS Feed & $10(100 \%)$ \\
\hline Notice of new articles & $9(90 \%)$ \\
\hline Trackback function & $9(90 \%)$ \\
\hline $\begin{array}{l}\text { Comment interaction } \\
\text { function }\end{array}$ & $9(90 \%)$ \\
\hline Blog searching function & $8(80 \%)$ \\
\hline Blog link function & $4(40 \%)$ \\
\hline Resources link function & $3(30 \%)$ \\
\hline
\end{tabular}




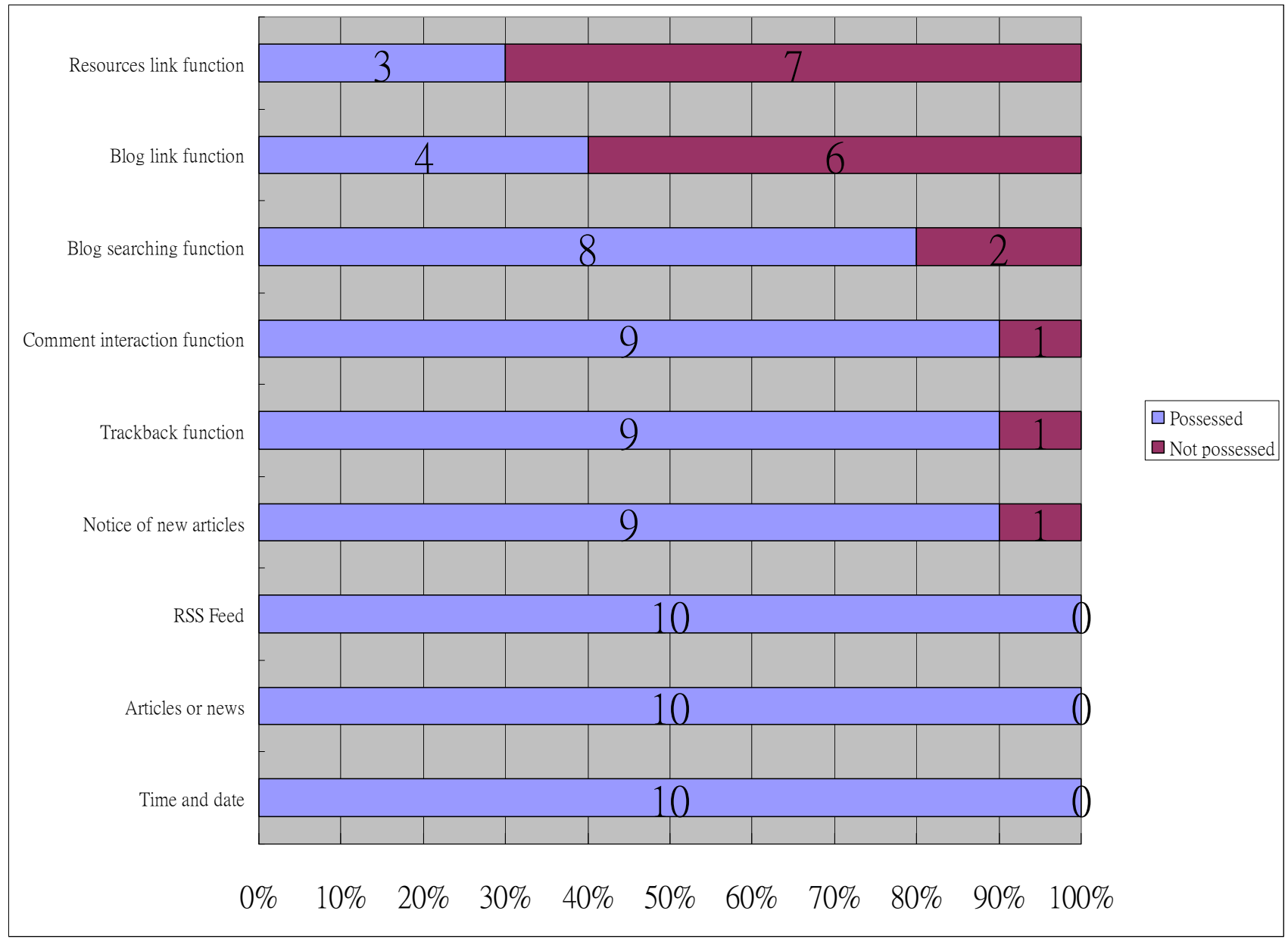

Chart 1. Analysis of the blog functions in Taiwanese high school libraries

Table 2. Statistics of the blog services in Taiwanese high school libraries

\begin{tabular}{|l|c|}
\hline Type of functions & Numbers (the ratio of each function item to the amount ) \\
\hline Provide new book information & $10(100 \%)$ \\
\hline Link web resources and on-line book club & $8(80 \%)$ \\
\hline Information about activities & $7(70 \%)$ \\
\hline Names of library & \\
\hline Link on-line book club & $7(70 \%)$ \\
\hline & \\
Link information about library & $6(60 \%)$ \\
\hline & $5(50 \%)$ \\
\hline & $5(50 \%)$ \\
\hline
\end{tabular}




\begin{tabular}{|l|c|}
\hline Link collections of library & $3(30 \%)$ \\
\hline Provide on-line suggestion box & $1(10 \%)$ \\
\hline & \\
Provide book review & $0(0 \%)$ \\
\hline
\end{tabular}

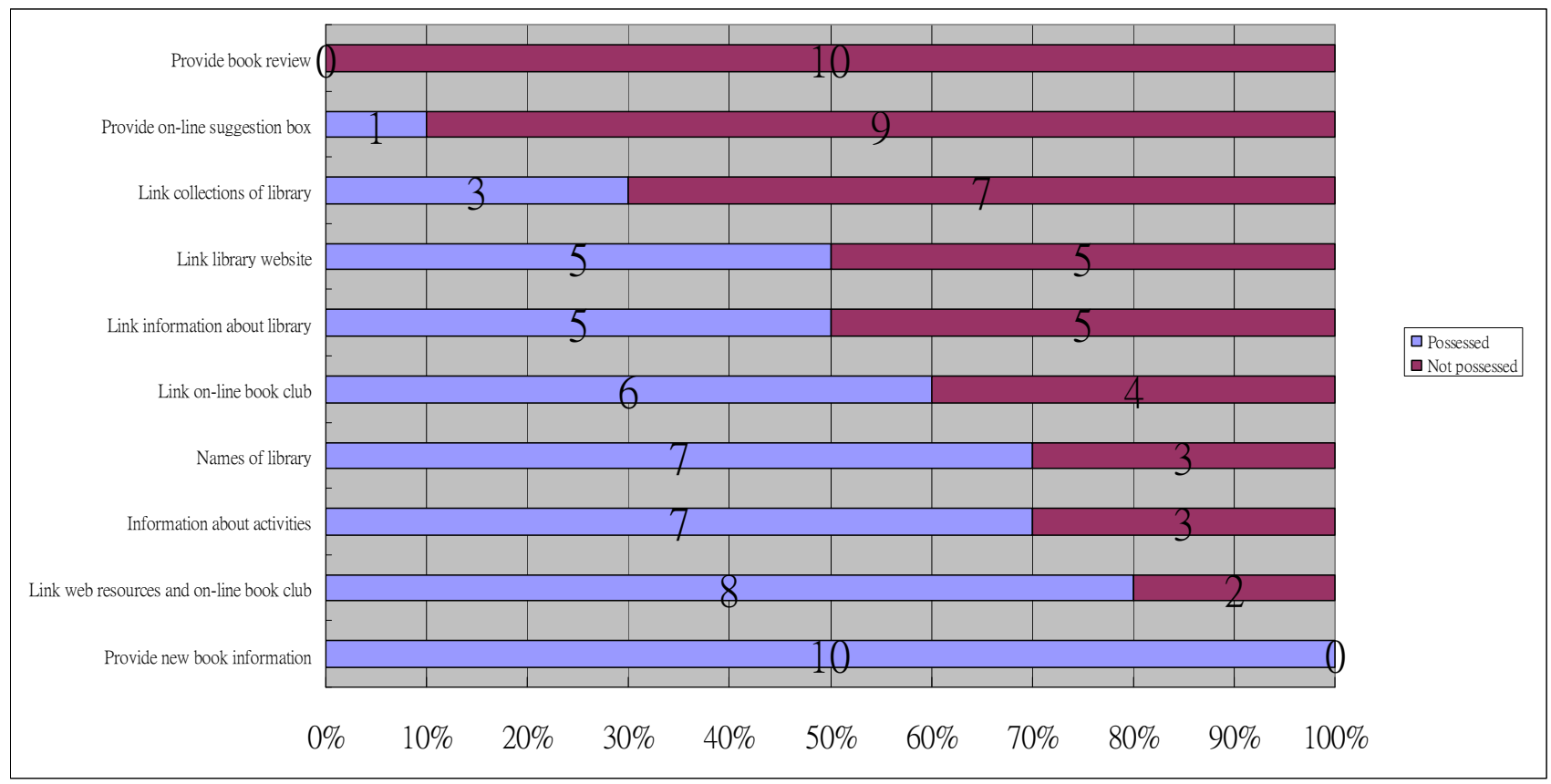

Chart 2. Analysis of the blog services in Taiwanese high school libraries

According to the three types of library blogs of Michael Stephens, "Marketing and Promotion Blog" is the major content type in high school libraries in Taiwan, and "Library News Blogs" and "Materials / Resources Blogs" are the successive content types. This result is similar to the results of Tu and $\mathrm{Ke}$ (2006) and Clyde (2004). (See Table 3 and Chart 3)

Table 3. Statistics of blog content types in Taiwanese high school libraries

\begin{tabular}{|l|c|c|}
\hline Types of content & Number & Ratio \\
\hline Marketing and Promotion Blogs & 6 & $60.0 \%$ \\
\hline Library News Blogs & 2 & $20.0 \%$ \\
\hline & & \\
Materials / Resources Blogs & 2 & $20.0 \%$ \\
\hline & & $100 \%$ \\
\hline
\end{tabular}




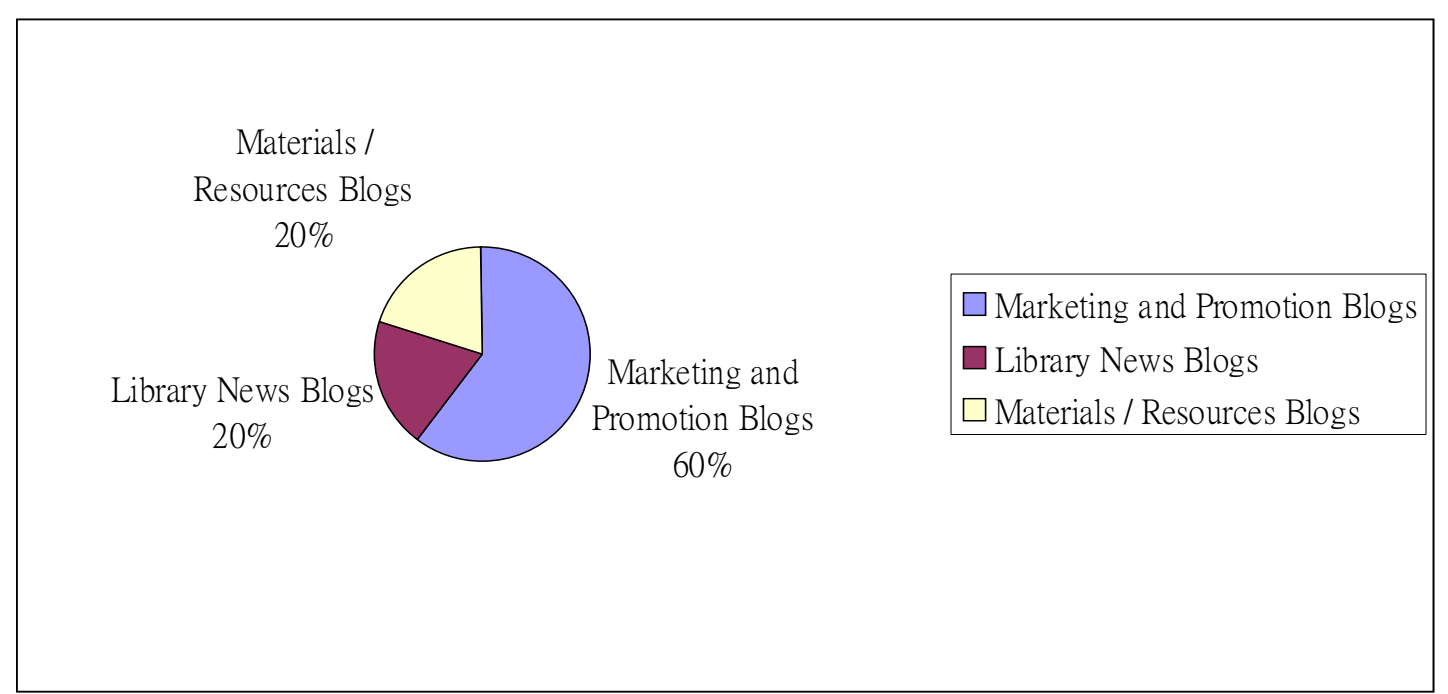

Chart 3. Analysis the blog content types in Taiwanese high school libraries

\section{(2) The period and the intention of applying blogs in high school libraries}

The period of applying the blogs by the high school libraries is still very short in terms of the result of the interview. Most of the libraries have set up the blogs since last year (April, 2004 to December, 2006). One of them is still on trial and hasn't announced in public yet. Seeing that the application of the blogs is still in the initial stage, the maintenance circle depends on the content of the library services. To cooperate with the activities and announcement of the libraries, the libraries deal with the maintenance circles as diverse as one week, two weeks, one month and two months. Therefore, the period of updating is different in different schools. Only one special school allows the students to issue comments after the registration; but others allow the librarians to revise. In the library aspect, the information or the media staffs take charge of technical maintenance, and the director of the library takes charge of content maintenance. Some of the librarians takes charge of providing the information, and the information staffs takes charge of all the other maintenance. The operation of the blogs is easier than that of the webpage, so the librarians can maintain the contents themselves. The libraries will need the information staffs to revise the technical parts.

The purposes to set up the blogs in every library can be different- to issue news, to provide the students to read in a lively environment, or to coordinate the instructional activities of the teachers. Some blogs of the high school libraries has substituted the original library websites to become the main communication approach.

\section{(3) The influence of blog services to the readers in high school libraries}

Most high school libraries believe that library blogs have little influence to the original hardcopy readers, whereas more influence to the on-line readers. To the libraries, the services they have to provide don't change a lot. The blog is an extra communication approach for the students, the teachers, the parents and other persons. Some of the librarians regard the blog as an increase of workload because they have to maintain the content at any time. However, most librarians think the way to issue the news and to maintain the contents of the blogs are easier and more immediate than those of the websites. 
The most distinctive influence after setting up the blogs in high school libraries is that the blog has substituted the original complex administrative system. Applying the blog not only makes the update more convenient and faster, but also makes the network reference resources organized more systematically for the teachers to share and communicate their correlative teaching materials. Besides, some of the libraries mentioned that the blog can create the reading surroundings by providing the recommendation booklists, the new collections (call number included), and the libraries can learn the reading affinity of the teachers and the students by the comments of every book to be the reference of ordering new books. In addition, in the effect of reader services, there is closer relationship between the libraries and the readers. Through the blogs, the readers can understand the operation and the business of the libraries; meanwhile, the readers and the librarians can communicate with each other more directly. Gradually, the reader will increase the frequencies of using the libraries.

\section{(4) The strike-rate of the anticipatory objective about the blog services to the reader services in high school libraries}

More than half the number of blogs in the high school libraries has reached the anticipatory objective about the reader services. For the most part, the blog provides the library information of news and activities to the teachers and students; some other blogs coordinate the teachers in teaching, holding all kinds of activities, having a discussion on certain subject, debating on-line to enforce the interaction and to increase the inclination and manners of the students to use the blogs.

A number of schools attempt to set up the library blogs, and most of them don't expect to reach the anticipatory objective about services. Generally speaking, the destined objectives include reading, promoting teaching activities (to make the parents and other persons involve in the library activities, to provide the choice articles), serving on-line readers (on-line book clubs, attainment discussion, new announcement, and new collection promotion), and more convenient updating. However, there are two schools fail to offer specific answer to the anticipatory objective about the reader services. One of them is in the test stage, and the other doesn't set a concrete objective. Surprisingly, the utility rate of the latter school is much higher than all of the other ones, and it also has more diverse functions. Altogether, more than half the number of the blogs in the high school libraries in this research has reached the anticipatory objective about the reader services.

\section{(5) Future management direction of the blogs in high school libraries}

In general, high school libraries would like to continue developing diverse blogs. "To provide more diversified services by using the blogs" is the aspirations commonly expressed by the 10 libraries. The diverse services of the blogs mean the way of "one channel, multidimensional development." For example, bulletin, on-line interaction, library utilizing education, and internal interactions among librarians. In addition, high school libraries also hope to apply the blogs to operate in coordination with the teaching process (like English learning services on the net, websites, postcast, and resources arrangement), with the related literary activities (like composition contests, book exhibitions). Overall, librarians have overcome most of the barriers in applying the blogs, but they still can proceed with enhancing the contents and increasing the quality of the staff: (i) the contents, to enhance the teaching resources (supplement of curriculum), book information (provide further basic information of 
books, like call number and collection location), diversified information (like classified according to classes, subjects, or contents); (ii) the staff, to increase the participation of the teachers and students, to recommend the blog to the whole school, to integrate the staff training and the resources improving. On the other hand, to carry out the blog system, the school libraries usually use the packaged software or apply to the network dealers; the staffs and the budget are limited, so there are not many requirements about the system.

\section{Discussion}

Most of the high school libraries are test-oriented for higher education, the more readers the better libraries are, and sometimes the quantification information about the number of library visitors and the number of books borrowed stands for the services of the libraries are successful or not. So the high school libraries tried their best to satisfy their readers, and to pull in more readers. At first, applying the blogs in high school libraries might face some problems about contents and techniques (like the decision of the contents and targets and the choice of setting up the system). The result of this study found that more than half of the librarians will use the blogs, which are habitually practiced by high school students, to broadcast information about the libraries, to provide the services of the libraries, and to become one of the announcement channels for the libraries. At the meantime, most of the librarians feel that it's much easier to learn the blogs than the previous system for broadcasting. This study also found that it was an extra burden to the limited manpower of the high school libraries to apply the blogs resulted from the workload. But the librarians still took an affirmative attitude toward the carrying on the blogs in the libraries. To deal with the school objective of test-oriented for higher education, yet many high school libraries are concerned for supporting the teaching task, having not enough in inducements to encourage students to use the blogs, and the network security of the blog software operated by the system manager. That's one of the reasons why the blogs can't be extensively applied in high school libraries. Furthermore, more than half of the school libraries had succeeded in applying the blogs to provide the services of the libraries, to combine the teaching activities, and to promote the libraries. So far, the reader services of the blogs in high school libraries have reached preliminary feasibility and extent. Improving the students' participation is one of the approaches to promote the blogs in high school libraries effectively. Besides, acquiring the support of the school, using library blog by the teachers to coordinate the teaching activities, the library staffs having the endurance enthusiasm to manage the blog, the contents having vigorousness and interaction, the above-mentioned approaches will likewise enable the blog to be applied in high schools successfully. Furthermore, there will be more subjects that are worth deliberating in the future: the selection of the library blog system, the elimination of the concern by the user to post articles in public, and the discussion about the copyright of the Trackback.

\section{References}

Chen, Wei-chu, \& Yang, Mei-hwa (2006). Marketing youth services with weblog of Public libraries. Interdisciplinary Journal of Taiwan Library Administration, 2(2), 54-64. [Text in Chinese].

Clyde, L. A. (1999). "The school library Web site: on the information highway or stalled in the carpark?", in Lighthall, L. and Howe, E. (Eds), Unleash the Power: Knowledge, Technology, Diversity: Papers Presented at the 3rd International Forum on Research in School Librarianship, Birmingham, Alabama, USA, November 10-14, 1999, International Association of School Librarianship, Seattle, WA, pp. 22737. 
Clyde, L. A. (2004). Blogs and school libraries. School Librarian, 52(4), 176-180.

Department of statistics, Ministry of Education, Republic of China (Taiwan) (2006). Lists of schools at all levels. Retrieved January 20, 2007, from http://www.edu.tw/EDU_WEB/EDU_MGT/STATISTICS/EDU7220001/service/sts4-1a.htm?open [Text in Chinese].

Fichter, D. (2001). Blogging your life away. Online, 25(3), 68-71.

Harder, G., \& Reichardt, R. (2003). Throw another blog on the wire: Libraries and the weblogging phenomena. Feliciter, 49(2), 85-88.

Hsieh, Pao-nuan (2005). Using Blog to market your library's services. Bulletin of the Taipei Public Library, 23(1), 1-9. [Text in Chinese].

Hung, Shu-fen (2006). The application of blogs in library services: Based on the characteristics and features of blogs and their current development. National Central Library Bulletin, 94(2), 27-71. [Text in Chinese].

Johnson County Library Community Information. (n. d. ). Retrieved March 7, 2007, from http://jclcommunityinfo.blogspot.com

LaMee, J. (2005, July). Market your library with a blog. ASSOCIATES, 12(1). Retrieved March 11, 2007, from http://associates.ucr.edu/705flam.htm

McPherson, K. (2006). School library blogging. Teacher Librarian, 33(5), 67-69.

Seng, Harris B.H. (Eds.). (1992). Library Reader Services. Taipei, Taiwan: Taiwan Xuesheng Shuju. [Text in Chinese].

Stephens, M. (2006). Blogs. Library Technology Reports, 42(4), 15-35.

Tu, Yu-chen, \& Ke, Hao-ren (2006). Blogs for Public libraries. Bulletin of the Taipei Public Library, 23(3), 3554. [Text in Chinese].

Wang, Ying-wen (2006). The application of social software in the academic library. Unpublished doctoral dissertation, National Chengchi University, Taiwan. [Text in Chinese].

Wang, Ying-wen, \& Yang, Mei-hwa (2006). The development and application of Library Blog. Bulletin of Library and Information Science, 56, 58-73. [Text in Chinese]. 